\title{
A política de simplificação e renúncia fiscal para as micro e pequenas empresas no Brasil e o pacto federativo: uma análise do Simples Nacional
}

\author{
The policies of tax breaks and collection simplification for micro and small business in \\ Brazil, and the federalist pact: an analysis of the National Simples Regime
}

\author{
Eduardo Rodrigues Gomes \\ Professor do Departamento de Ciência Política, \\ Universidade Federal Fluminense - UFF \\ e-mail: gomeduar@gmail.com
}

\section{Fabrícia Guimarães}

Doutora em Ciência Política,

Universidade Federal Fluminense - UFF

e-mail: guimaraesfabricia@gmail.com
Recebido: $18 / 09 / 2012$

Aceito: 29/11/2012
RESUMO Este trabalho consiste em uma análise da implementação do Regime Especial Unificado de Arrecadação de Tributos e Contribuições das Microempresas e Empresas de Pequeno Porte (MPEs), o Simples Nacional, que se constitui numa ambiciosa política de renúncia fiscal e simplificação tributária da União e todos os entes subnacionais da federação em favor das MPEs, trazendo naturalmente à tona tensões entre essas unidades e o poder central. Dessa forma, estaremos analisando como foi possível resolver os problemas de autonomia subnacional e coordenação entre os diferentes entes federados na implementação do Simples Nacional; o papel dos outros autores como o Sebrae e o Legislativo e os tipos de recursos que foram mobilizados para aquele objetivo. O trabalho focaliza o processo político de construção deste novo regime, examinando de que forma as várias questões políticas e os diversos dilemas técnicos derivados da estrutura federativa do país foram enfrentados e solucionados. O artigo explica as características do Simples Nacional e seu processo de formulação e implementação, ressaltando o papel do Comitê Gestor que privilegiava a União, a criação de um sistema de informações sobre os tributos acessível a todos os envolvidos e um instrumentos administrativo inovadores que reduzia tensões do nossas unidades federativas para um nível manejável. Por último, mas não menos importante, introduzimos a questão dos custos difusos ara a sociedade, de políticas de renúncia fiscal como esta.

PALAVRAS-ChaVe Micro e pequenas empresas; Políticas públicas; Simples Nacional; Federalismo.

ABSTRACT This study is an analysis of the implementation of the Special Regime of Simplification and Reduction of Tax Collection for Micro and Small Business (MSEs), the National Simples, which constitutes an ambitious policy of Brazil's Union involving all subnational autonomous units of the country's federation, in favor of MSEs, naturally bringing out tensions between these units, and the central power. To this extent, we will be analyzing how it was possible to solve the problems of subnational autonomy and coordination among these different federal units in implementing the National Simples: the role of other actors as Sebrae, the 
Legislative, as well as the political and administrative resources that were mobilized towards that goal. The paper focuses on the political process of constructing this new tax regime, examining how a number of political issues and technical dilemmas, derived from the country federalist structure, were dealt with, and solved. In sum, the article explains the characteristics of National Simples, and its process of formulation and implementation, emphasizing the role of a Steering Committee that privileged the Union, the creation of a system of information access about the taxes for everyone involved, and of other innovative administrative provision that reduced the tensions of our unequal federalist units to a manageable level. Last, but not the least, we also introduce the issue of pervasive costs of tax breaks for society in general in policies such as this one.

KEYWORDS Micro and small business; Public policies; National Simples; Federalism.

\section{Introdução}

Este trabalho consiste em uma análise da implementação do Regime Especial Unificado de Arrecadação de Tributos e Contribuições das Microempresas e Empresas de Pequeno Porte (MPEs), o Simples Nacional. O Simples Nacional é uma das principais iniciativas do governo federal de apoio as MPEs, formada por uma política de renúncia fiscal e simplificação tributária da União e todos os entes subnacionais da federação em favor das MPEs, trazendo naturalmente à tona as tensões entre essas unidades.

Com o processo de descentralização da Constituição de 1988, os municípios alcançaram a condição de ente federado, da qual faz parte a autonomia tributária, fiscal e política que tende a limitar a autoridade do governo federal frente aos governos estaduais e locais (Arretche, 2004). Nesse sentido, a cooperação entre eles passa a ser uma variável importante para a formulação e execução de políticas públicas (Sarak, 2010), como a que aqui se analisa.

O Simples Nacional tem implicações diretas na autonomia dos entes federados e seu processo de implementação enfrentou uma série de questões políticas, sendo que algumas derivaram de dilemas técnicos. De qualquer forma, a trajetória das políticas para MPEs envolveu várias tentativas e discussões sobre a simplificação tributária para MPEs seja por meio da cobrança unificada do ICMS ou de isenções de impostos estaduais e municipais. Com o estudo dos avanços alcançados por meio do Simples Nacional, esperamos contribuir para a análise do processo de implementação de políticas públicas no Brasil, que, como destacou Faria (2003) é uma área pouco explorada pela literatura nacional.
Dessa forma, estaremos analisando, ao longo do texo, como foi possível resolver os problemas de autonomia e coordenação entre os diferentes entes federados na implementação do Simples Nacional. Qual foi o papel dos outros atores como o Sebrae e o Legislativo? Que tipos de recursos foram mobilizados? Dito isto, fica claro que o processo político deste modelo é o eixo deste paper, que visa examinar os desafios de coordenação e controle na implementação do Simples Nacional, considerando também o instrumento administrativo que viabilizou este sistema unificado de arrecadação, fiscalização e cobrança compartilhado entre União, Estados e municípios.

Mais do que isso, se a implementação desta e de outras políticas públicas pode ser vista sob a perspectiva linear do ciclo da política pública (formação de agenda, formulação, implementação e avaliação), segundo a qual ela é não é mais que uma etapa de execução das atividades previstas na formulação, a realidade é mais complexa. Uma visão mais apropriada mostra que "[...] o processo de formação de uma política se dá a partir da interação entre formulação, implementação e avaliação [...]", sem uma sequência linear (Menicucci, 2007: 33). No caso do Simples Nacional, sua implementação provocou novas redefinições, construindo esta política de forma dinâmica e buscando seu aperfeiçoamento.

Após esta introdução, trataremos, de um lado, das características do Simples Nacional e, de outro, do seu processo de formulação e implementação, ressaltando o papel do Comitê Gestor e introduzindo, também, a questão dos custos difusos de políticas de renúncia fiscal. Depois das reflexões feitas acerca das 
principais questões levantadas anteriormente, sobre a formulação e implementação do Simples Nacional, apresentamos, na terceira e última parte, uma síntese dos principais aspectos que vieram a caracterizar esta nova política para as MPEs.

\section{Simples Nacional: Formulação e Implementação}

\section{Características}

A origem do Simples Nacional está na aprovação da Emenda Constitucional (EC) n ${ }^{\circ} 42$ de 2003, que previa a instauração de lei complementar dispondo sobre a definição de tratamento diferenciado e favorecido para as microempresas e para as empresas de pequeno porte (MPEs) e sobre a instituição de um regime único de arrecadação dos impostos e contribuições da União, Estados, Distrito Federal e Municípios. A longo prazo, o Simples Nacional preenche o requisito constitucional de tratamento diferenciado da pequena empresa presente nos artigos 170 e 179 da Constituição federal de 1988, visando incentivá-las pela simplificação, eliminação ou redução de suas obrigações administrativas, tributárias, previdenciárias e creditícias.

A EC no 42/2003 (Brasil, 2003a) estabelecia, no entanto, importantes condições as quais o regime único de arrecadação deveria satisfazer, revelando a atenção do legislador com a autonomia política, administrativa, tributária, orçamentária e fiscal que os entes federados possuem. Elas são:

- Ser opcional para o contribuinte;

- Ser possível estabelecer condições de enquadramento diferenciadas por Estado;

- Permitir que o recolhimento fosse unificado e centralizado e a distribuição da parcela de recursos pertencentes aos respectivos entes federados fosse imediata, vedada qualquer retenção ou condicionamento;

- Permitir que a arrecadação, a fiscalização e a cobrança pudessem ser compartilhadas pelos entes federados, adotado um cadastro nacional único de contribuintes.

A regulamentação da $\mathrm{EC} \mathrm{n}^{\circ}$ 42/2003 ocorreu com a aprovação, em 14 de dezembro de 2006, da Lei Complementar (LC) no 123/2006, conhecida como Lei Geral da MPEs (Brasil, 2006). A lei determinou uma série de benefícios para as MPEs, entre eles, a instituição do Simples Nacional a partir de julho do ano seguinte, sob a alegação da necessidade de um tempo maior para estruturar um sistema informatizado para concretizar estes incentivos.
Além do Simples Nacional, o novo estatuto das MPEs previa a simplificação do processo de abertura, alteração e encerramento das MPEs, a dispensa do cumprimento de certas obrigações trabalhistas e previdenciárias, o estímulo à inovação tecnológica, o incentivo ao associativismo, a regulamentação da figura do pequeno empresário e o estabelecimento de critérios simplificados para participação de MPEs em licitações públicas. Para estes aspectos não tributários, a lei estabeleceu que a responsabilidade seria do Fórum Permanente das Microempresas e Empresas de Pequeno Porte, presidido e coordenado pelo Ministério do Desenvolvimento, Indústria e Comércio Exterior. Competiria ao Fórum a articulação e promoção da regulamentação destes aspectos, além do acompanhamento de sua implementação.

Entretanto, o foco deste trabalho é o Simples Nacional, enquanto um regime tributário, destinado às MPEs, que permite a unificação da arrecadação, fiscalização e cobrança dos seguintes tributos: Imposto sobre a Renda da Pessoa Jurídica (IRPJ); Imposto sobre Produtos Industrializados (IPI); Contribuição Social sobre o Lucro Líquido (CSLL); Contribuição para o Financiamento da Seguridade Social (COFINS); Contribuição para o PIS/Pasep; Contribuição Patronal Previdenciária (CPP), de competência federal; o Imposto sobre Operações Relativas à Circulação de Mercadorias e Sobre Prestações de Serviços de Transporte Interestadual e Intermunicipal e de Comunicação (ICMS), de competência estadual e o Imposto sobre Serviços de Qualquer Natureza (ISS), de competência municipal.

Com a inclusão destes dois últimos impostos estaduais e municipais o Simples Nacional diferencia-se do regime anterior, o Simples Federal, instituído em 1996 e denominado Sistema Integrado de Pagamento de Impostos e Contribuições das Microempresas e Empresas de Pequeno Porte. Quando foi implementado, o Simples Federal significou uma grande novidade no campo da simplificação tributária, já que, com a sua inscrição, foi possível unificar impostos e contribuições federais. Além da unificação, o sistema definiu alíquotas menores para o segmento das MPEs.

Por sua vez, ainda em 1996, os estados e municípios foram autorizados a firmar convênio com o governo federal e permitir, assim, a agregação de seus impostos (ICMS e ISS) ao Simples Federal. O ICMS é o imposto mais crítico nesse arranjo, porque indica a desigualdade na arrecadação de tributos entre os entes federados. Municípios de um mesmo Estado e com tamanhos semelhantes apresentam grande disparidade de arrecadação (Arretche, 2004). 
Embora os convênios com o governo federal não tivessem sido instalados em número significativo, cumpre ressaltar que quase todos os estados estabeleceram políticas tributárias diferenciadas para o setor, em alguns casos de forma similar ao Simples Federal, concretizando o apoio às MPEs. Viol e Rodrigues (2000) mostraram que cada governo definiu limites próprios de conceituação de MPEs e aplicou regras particulares, de acordo com a realidade local, para a arrecadação de seus tributos.

Assim, no estado de São Paulo foi instituído o Simples Paulista, através da Lei estadual n ${ }^{\circ} 10.086 / 98$, segundo a qual as microempresas seriam aquelas com receita bruta anual até $\mathrm{R} \$ 83.700,00$ e teriam direito à isenção do ICMS. A partir deste valor até $\mathrm{R} \$ 720.000,00$ eram consideradas pequenas empresas e teriam uma alíquota reduzida para pagamento de ICMS. Estes valores de enquadramento foram atualizados em legislação posterior. No Distrito Federal, a Lei no $2.510 / 99$ estabeleceu um tratamento tributário favorecido para MPEs e incluiu também feirantes e ambulantes (Viol e Rodrigues, 2000). As assimetrias da federação foram retratadas da seguinte forma por estes autores:

Esses são exemplos que mostram a convivência simultânea de diversos sistemas de tratamento favorecido no País, que são similares ao SIMPLES, mas buscam adaptar-se à política de desenvolvimento local. De novo, vale salientar que, apesar de não ser a situação mais benéfica do ponto de vista do contribuinte, é o modo de conciliar a concessão de benefícios com a manutenção da autonomia tributária dos governos subnacionais (Viol e Rodrigues, 2000: 50).

Com a entrada em vigor da Lei Geral da MPE, em 2006, o Simples Federal foi revogado. A Lei Geral da MPE definiu os parâmetros de apoio da ação governamental em prol do segmento e estabeleceu o limite de até $\mathrm{R} \$ 240.000,00$ de receita bruta anual para classificar a microempresa, ao passo que a pequena empresa devia apresentar receita bruta anual na faixa entre $R \$ 240.000,00$ e $R \$ 2.400 .000,00$, que veremos à frente. Todavia, em 2011, conforme mostra o Quadro 1, uma nova legislação alterou os limites para as MPEs, entrando em vigor em 2012.

Para poder optar pelo Simples Nacional é necessário que a empresa esteja dentro dos limites de enquadramento para MPEs definidos pela legislação e não seja atingida pelas vedações determinadas na lei. Estes impedimentos podem ser quanto à atividade exercida pela empresa ou quanto a sua composição. Por exemplo, não podiam entrar no Simples Nacional as MPEs que tivessem sócio domiciliado no exterior ou de cujo capital participasse entidade da administração pública, direta ou indireta, federal, estadual ou municipal.

Mais do que isso, mesmo limitando a entrada neste regime de uma série de atividades, muitas empresas, especialmente da área de serviços, que estavam impedidas de fazer parte do Simples Federal passaram a ser permitidas no Simples Nacional, em uma ampliação significativa dos possíveis beneficiários do novo regime.

Em alguns estados, o enquadramento de pequenas empresas, definido pela receita bruta anual até $\mathrm{R}$ \$2.400.000,00, significaria uma redução expressiva e até mesmo uma ausência de grandes empresas. Para resolver esta questão os estados e municípios poderiam optar pela aplicação de faixas de receita bruta anual com limites diferenciados, de acordo com a participação daqueles no Produto Interno Bruto (PIB), para efeito do recolhimento do ICMS e ISS na forma do Simples Nacional, conforme mostra o Quadro 2. Esta medida foi o elemento que possibilitou a aplicação de uma política nacional a um Estado federalista, formado por unidades muito desiguais, sob os mais diversos aspectos. Enfim, houve uma equalização, entre os entes federados, que permitiria a constituição de um regime unificado e compartilhado de arrecadação, distribuição e fiscalização, que foi buscado por décadas e cuja dinâmica poderá ser vista no próximo item desta segunda parte.

Também foi estabelecido um maior número de alíquotas diferenciadas e progressivas por setor e subsetor de atividade de acordo com faixas de receita bruta anual, através de tabelas de tributação. Estas tabelas estavam em cinco anexos da lei, sendo que o

Quadro 1. Limites de receita bruta anual para enquadramento dos tipos de pequenas empresas e do microempreendedor individual - 2012 .

\begin{tabular}{|ll|}
\hline \multicolumn{1}{|c|}{ Definição } & \multicolumn{1}{c|}{ Receita bruta anual } \\
\hline Microempresa & até $\mathrm{R} \$ 360.000,00$ \\
Pequena Empresa & de $\mathrm{R} \$ 360.000,00$ a $\mathrm{R} \$ 3.600 .000,00$ \\
Microempreendedor Individual & até $\mathrm{R} \$ 60.000,00$ \\
\hline
\end{tabular}

Fonte: Brasil, 2011 
Quadro 2. Limites diferenciados para efeito do recolhimento do ICMS e ISS na forma do Simples Nacional, de acordo com a participação dos Estados no Produto Interno Bruto (PIB).

\begin{tabular}{|llc|}
\hline \multicolumn{1}{|c|}{ Até $\mathbf{1 \%}$ do PIB } & De $\mathbf{1 \%}$ a 5\% do PIB & Acima de 5\% do PIB \\
\hline Faixas até R\$ 1.200.000,00 & Faixas até R\$ 1.800.000,00 & Faixas até R\$ 2.400.000,00 \\
\hline Acre & Amazonas & Minas Gerais \\
Alagoas & Bahia & Paraná \\
Amapá & Ceará & Rio de Janeiro \\
Maranhão & Distrito Federal & Rio Grande do Sul \\
Paraíba & Espírito Santo & São Paulo \\
Piauí & Goiás & \\
Rio Grande do Norte & Mato Grosso & \\
Rondônia & Mato Grosso do Sul & \\
Roraima & Pará & \\
Sergipe & Pernambuco & \\
Tocantins & Santa Catarina & \\
\hline
\end{tabular}

Fonte: Sebrae (2007). Lei Geral das MPEs.

anexo V possuía as alíquotas mais elevadas, situação em que era necessário fazer uma equação entre folha de salários e receita bruta. As empresas sujeitas a este anexo teriam uma tributação maior, tornando a opção pelo Simples Nacional atrativa apenas para aquelas que possuíssem uma significativa folha de salários. A intenção do governo era beneficiar empresas que empregassem mais pessoas e desestimular profissionais autônomos a se tornarem pessoa jurídica.

O desafio de assegurar a autonomia dos entes federados, como mostra Santiago (2011), foi enfrentado através da gestão compartilhada por meio do CGSN, que veremos com mais detalhes no próximo item, e da preservação da autonomia operacional que cada ente federado possui. Esta autonomia operacional

[...] abrange o poder de aprovar pedidos de opção ao regime, praticar atos de ofício que incluam ou excluam empresas, exercer o controle de obrigações principais ou acessórias e empreender ações fiscais. (Santiago, 2011: 31).

O Simples Nacional foi alterado por 4 leis complementares posteriores. As três primeiras alterações ocorreram no governo Lula e tratavam da modificação do enquadramento de algumas atividades em relação aos anexos tributários e do estabelecimento de regras relativas ao Microempreendedor Individual (MEI), principalmente.

No governo Dilma Rousseff, mais uma alteração foi feita ampliando o limite de receita bruta anual das MPEs para efeito de enquadramento no Simples Nacional. Também estabeleceu a criação de limite adicional de receita bruta para exportação de mercadorias e parcelamento de débitos apurados no Simples Nacional, apesar de, anteriormente, empresas com débitos não poderem aderir ao regime, sendo que tudo isso está sintetizado no Quadro 3.

A LC n ${ }^{\circ}$ 128/2008 (Brasil, 2008) ampliou o alcance do Simples Nacional, ao incluir, por exemplo, novos segmentos econômicos e criar o MEI, voltado para a legalização do trabalhador por conta própria. $\mathrm{O}$ MEI fica enquadrado no Simples Nacional e isento de tributos federais: IRPJ, PIS, Cofins, IPI e CSLL, mas pagaria um valor fixo mensal destinado à previdência e ao ICMS ou ISS, garantindo o acesso a benefícios como auxílio maternidade, auxílio doença, aposentadoria, entre outros. Outras alterações foram: a transferência dos escritórios contábeis para um anexo com alíquota menor; a inserção de outras classes no programa do Simples Nacional; a alteração e aprimoramento do Anexo V da Lei Geral; a possibilidade de MPEs optantes pelo Simples Nacional realizarem negócios de compra e venda de bens, para os mercados nacional e internacional, por meio de Sociedade de Propósito Específico; além de outros avanços que visavam à desburocratização.

Esta lei também criou outro órgão administrativo que é o Comitê para Gestão da Redesim. Este Comitê ficaria responsável por regulamentar a inscrição, cadastro, abertura, alvará, arquivamento, licenças, permissão, autorização, registros e demais itens relativos à abertura, legalização e funcionamento de empresários e de pessoas jurídicas de qualquer porte, atividade econômica ou composição societária. 
Quadro 3. Síntese das alterações da EC que instituiu o Simples Nacional.

\begin{tabular}{|cl|}
\hline \multicolumn{1}{|c|}{ Norma } & \multicolumn{1}{c|}{ Principais mudanças } \\
\hline LC n ${ }^{\circ} 127 / 2007$ & $\begin{array}{l}\text { Migração de atividades do setor de serviço do Anexo V, do Simples Nacional, para o Anexo III, } \\
\text { onde as alíquotas de tributação são mais baixas. }\end{array}$ \\
LC n ${ }^{\circ} 128 / 2008$ & $\begin{array}{l}\text { Estabelece regras quanto ao microempreendedor individual e promove várias mudanças em relação } \\
\text { ao Simples Nacional } \\
\text { LC n }{ }^{\circ} 133 / 2009\end{array}$ \\
$\begin{array}{l}\text { Modifica o enquadramento das atividades de produções cinematográficas, audiovisuais, artísticas e } \\
\text { culturais no Simples Nacional. }\end{array}$ \\
$\begin{array}{l}\text { Aumenta o limite de enquadramento de MPEs, benefícios para a exportação e diminuição de } \\
\text { algumas alíquotas. }\end{array}$ \\
\hline
\end{tabular}

Fonte: Brasil, 2007; 2008; 2009; 2011

Já a LC nº 133/2009 (Brasil, 2009) favoreceu as atividades de produções cinematográficas, audiovisuais, artísticas e culturais no Simples Nacional, o que gerou o apelido de "Simples da cultura". Esta norma reduziu a carga tributária das MPEs do setor cultural, que passaram a ser tributadas pelo anexo III da Lei Geral, e permitiu a entrada no grupo de beneficiários do Simples Nacional, das MPEs que se dedicassem à exibição ou apresentação de música, teatro, dança, cinema, audiovisual, literatura e artes visuais.

A legislação de 2011, que entrou em vigor em 2012, permitiu o parcelamento da dívida ativa junto ao Simples Nacional e a criação de limite adicional de receita bruta para exportação de mercadorias, além da ampliação dos valores de enquadramento conforme apresentado anteriormente.

Dessa forma, vemos que a Lei Geral das MPEs acabou por ter a presença de demandas recorrentes, por exemplo, a favor do aumento dos limites de enquadramento e da inclusão de outros setores da atividade econômica. Com a diferenciação de alíquotas também surgem demandas voltadas para inclusão ou transferência para tabelas de tributação mais favoráveis. Nesse sentido, a dinâmica da implementação também é verificada na realização de ajustes e melhorias, segundo demonstram os exemplos acima.

Frente aos desafios que se delineavam, foi instituído, pelo Decreto $\mathrm{n}^{\circ}$ 6.038, de 7/2/2007 (Brasil, 2007), o Comitê Gestor do Simples Nacional (CGSN) com o objetivo de gerir e normatizar os aspectos tributários do Simples Nacional, de forma compartilhada entre os entes federados.

O Comitê é formado por quatro representantes da Secretaria da Receita Federal do Brasil (RFB), dois representantes dos estados, indicados pelo Conselho Nacional de Política Fazendária (Confaz), e dois representantes dos municípios, sendo um indicado pela Confederação Nacional de Municípios (CNM) e outro pela Associação Brasileira das Secretarias de Finanças das Capitais (Abrasf). O presidente do CGSN é escolhido entre os representantes da União. Com quatro dos seus oito integrantes representando a União, esta acaba por conquistar uma posição mais vantajosa.

O comitê também conta com uma Secretaria Executiva, cuja finalidade é prestar apoio institucional e técnico-administrativo necessário ao desempenho das competências do CGSN. Este órgão teve um papel muito importante na viabilização do Simples Nacional, pois foi com base em seu funcionamento e atuação que se logrou facilitar o apoio dos estados e municípios à Lei Geral. Após apresentarmos as características do Simples Nacional, vamos retroceder ao momento de sua formulação de forma a acompanharmos as preocupações e debates surgidos até sua implementação.

\section{Formulação e implementação}

A formulação do Simples Nacional surgiu com a discussão em torno da reforma tributária apresentada pelo então recém-eleito, Presidente Luís Inácio Lula da Silva, através da Proposta de Emenda Constitucional (PEC) no 41/2003 (Brasil, 2003b). O ponto central da proposta era a criação de uma legislação nacional para o ICMS, que substituiria as 27 legislações estaduais, além da simplificação da estrutura de alíquotas. Paralelamente aos debates provocados pela discussão da reforma tributária, os representantes dos micro e pequenos empresários começaram a se articular.

Foi nesse clima que, em março de 2003, o Movimento Nacional da Micro e Pequena Empresa (Monampe), a Associação Brasileira dos SEBRAE Estaduais (Abase) e o Serviço Brasileiro de Apoio às Micro e Pequenas Empresas (Sebrae) organizaram uma oficina de trabalho, em Brasília, com o objetivo de discutir as reformas tributária, previdenciária e trabalhista sob a ótica do micro e pequeno empresário 
e, com isso, produzir propostas que pudessem ser encaminhadas ao governo federal. O Conselho Deliberativo Nacional do Sebrae definiu como prioridade institucional a melhoria do ambiente legal para as MPEs, visando seu desenvolvimento e sobrevivência.

O Sebrae começou a articular o apoio do governo, partidos e organizações empresariais, visando introduzir no capítulo sobre o sistema tributário nacional a possibilidade do tratamento tributário diferenciado e simplificado para as MPEs, por meio de lei complementar, o que garantiria um tratamento uniformizado ao setor nas esferas federal, estadual e municipal. A entidade mobilizou e organizou ações nos Estados, como a formação de grupos de discussão e aplicação de questionários padronizados com a finalidade de obter subsídios para a elaboração de um projeto para o segmento (Sebrae, 2004).

Dessa forma, após quase oito meses de tramitação, a PEC foi aprovada e transformada na $\mathrm{EC} \mathrm{n}^{\circ} 42 / 2003$, que como vimos incluía a possibilidade de um regime único de arrecadação dos impostos e contribuições da União, dos estados, do Distrito Federal e dos municípios para os micro e pequenos empresários, a ser regulamentado por lei complementar.

Uma série de projetos de lei e propostas de organizações empresariais foram formulados visando a regulamentação da emenda constitucional, com destaque para a atuação do Sebrae nesse sentido, agindo intensamente por meio de mobilizações nos estados, recolhendo opiniões e sugestões dos empresários, realizando estudos e, por fim, condensando essas informações na elaboração de um anteprojeto de lei.

$\mathrm{A} \mathrm{EC} \mathrm{n}^{\circ}$ 42/2003 criou a possibilidade de formação de um mecanismo de arrecadação de tributos e contribuições devidos em todos os entes da federação de forma unificada, o que representaria menores custos para as MPEs. Também acabaria com a diversidade de normas de enquadramento e alíquotas que foram adotadas por vários estados na criação de seus próprios regimes diferenciados para as MPEs. $\mathrm{Na}$ verdade, essa unificação representava um grande desafio para a regulamentação desta norma, uma vez que teria que lidar com questões relativas à autonomia política dos entes da federação.

Para o economista e jornalista Luis Nassif, a ideia de um regime unificado para a MPE poderia servir como um laboratório para mudanças nos paradigmas fiscais, trabalhistas e creditícios do país. Como as MPEs respondiam por $20 \%$ do PIB, mas apenas $4 \%$ de arrecadação tributária, sua lógica era de que se a lei desse errado o país perderia pouco, mas se tivesse êxito traria empresas para a formalidade, aumentando assim a arrecadação (Nassif, 2003).

Os obstáculos para esse desfecho não eram poucos. Em 2004, foi apresentado pelo deputado Juthay Junior o projeto de lei complementar, PLC no 123/2004, (Brasil, 2004a) que tratava da regulamentação da EC $n^{\circ} 42 / 2003$. A tarefa de unificar impostos federais, estaduais e municipais, mexendo com a autonomia tributária que os entes da federação possuem, era de grande complexidade. Por exemplo, em estudo realizado pelo consultor legislativo da Câmara, Adriano Nóbrega Silva, comparando o substitutivo da Comissão de Desenvolvimento Econômico, Indústria e Comércio (CDEIC), o PLC n ${ }^{\circ}$ 123/2004 (Brasil, 2004a) e o PLC n 125/2004 (Brasil, 2004b), apensado ao projeto inicial, o autor afirmava que

[...] nenhum dos projetos atendia satisfatoriamente os propósitos a que se destinavam, demandando uma melhor reflexão sobre a instituição do chamado Simples Nacional no ordenamento jurídico brasileiro [...] (Silva, 2005: 17).

Já em 2005, alguns fatos favoreceram o andamento do projeto, por exemplo, com a presidência do Sebrae sendo assumida por Paulo Okamoto, conhecido amigo do presidente Lula e o interesse do governo pelo seu projeto de lei complementar sobre a Pré-Empresa, que acabou apensada ao projeto da Lei Geral. O projeto da Pré-Empresa, seguia os mesmos princípios da Lei Geral da MPE instituindo regime tributário simplificado, a criação de um comitê gestor e medidas de desburocratização. O objetivo era formalizar o pequeno empreendedor, promovendo, além disso, a inclusão previdenciária do próprio empreendedor e de seus empregados. Essas questões migraram para o debate da Lei Geral, que incorporou em grande parte o projeto do Executivo através da figura do "pequeno empresário".

Em abril, o projeto chegou à Comissão Especial da Microempresa, cujo relator era o deputado Luiz Carlos Hauly, membro titular da Comissão de Finanças e Tributação, ex-secretário de Fazenda do Paraná e com experiência em tributação e administração pública. Foi nesta comissão que os interesses foram mobilizados, com trabalhos que incluíram análise de projetos apensados, audiências públicas, apresentação de emendas, e, por fim, como resultado de todos esses debates, a elaboração de substitutivo.

Ainda em abril, no dia 12, foi lançada a Frente Empresarial pela Aprovação da Lei Geral, em São Paulo, promovendo ações em todos os estados brasileiros, ouvindo queixas e sugestões dos empresários e pressionando pela aprovação rápida da Lei Geral. A frente era liderada pela Confederação 
Nacional da Indústria (CNI), Confederação Nacional do Comércio (CNC), Confederação Nacional da Agricultura (CNA), Confederação Nacional dos Transportes (CNT), Confederação Nacional das Instituições Financeiras (CNF) e das Associações Comerciais e Empresariais do Brasil (CACB), com apoio do Sebrae.

As mobilizações pela aprovação da Lei Geral da MPE envolveram a organização de carreatas, debates, seminários e panfletagens, além de outras formas de sensibilização. O ponto alto de toda essa movimentação ocorreu em 8 de junho, quando a Frente Empresarial pela Lei Geral liderou uma marcha com a participação de quatro mil empresários e líderes empresariais, em Brasília, para a entrega, em ato público, do anteprojeto da Lei Geral, elaborado pelo Sebrae, ao Presidente Lula e aos presidentes do Senado, Renan Calheiros, e da Câmara dos Deputados, Severino Cavalcanti.

Entre maio e novembro de 2005, a Comissão Especial realizou audiências públicas ${ }^{1}$ com nomes relacionados à questão. Foram ouvidos representantes de organismos das MPEs, como o presidente da Conempec (Confederação Nacional das Entidades de Micro e Pequenas Empresas do Comércio e Serviços), José Tarcísio da Silva, e o presidente do Sebrae, Paulo Okamoto; das grandes organizações da estrutura corporativa: o deputado federal Armando Monteiro, presidente da CNI e o presidente da FIESP, Paulo Skaf; especialistas da área de tributação como o ex-secretário da Receita Federal, Everardo Maciel e o secretário de fazenda da Bahia e coordenador do Confaz, Albérico Machado Mascarenhas. Foram igualmente entrevistados representantes de setores que defendiam sua entrada, ou manutenção, no Simples nacional, como foi o caso do presidente do Sindicato das Indústrias de Explosivos no Estado de Minas Gerais (Sindiemg), Sidônio Fernandes do Couto.

Os participantes debateram as três propostas: a do Executivo, que era o PLC n ${ }^{\circ}$ 210/2004 (Pré-Empresa), o substitutivo da CDEIC e a proposta do Sebrae. Entre os temas que suscitaram vários debates encontravam-se

\footnotetext{
A lista completa de participantes incluía, além dos já citados, Eduardo Prates Octaviani Bernis, presidente da Associação Comercial de Minas Gerais, Luiz Carlos Dias Oliveira, diretor-secretário da FIEMIG, representando o presidente da instituição Robson Braga de Andrade; Heron Arzua, secretário da Fazenda do Paraná, a respeito das experiências estaduais na concessão de incentivos a microempresas; Lina Maria Vieira, secretária da Fazenda do Rio Grande do Norte; Luiz Otávio Possas Gonçalves, presidente do SindBebidas/MG; Luigi Nesse, da Confederação Nacional dos Serviços (CNS) e Maurício Laval Pina de Souza Mugnaini, presidente da Federação Nacional das Empresas de Informática (Fenainfo) e Milton Bogus, diretor do Departamento da Micro, Pequena e Média Indústria da FIESP.
}

o modo como seria feita a fiscalização tributária das empresas, já que os três níveis da federação estariam envolvidos, a exclusão do setor de serviços do Simples Nacional, a flexibilização trabalhista e a importância de se incluir o Simples Trabalhista. Os debates e as propostas de projetos de lei apresentadas e apensadas ao PLC n ${ }^{\circ} 123 / 2004$ levaram o relator a optar pela fusão do PLC n 210/2004 e do Projeto da Lei Geral da MPE, do Sebrae, num único texto, que ampliou significativamente o conteúdo da proposta legislativa, indo além da questão tributária ao incluir matérias como criação de cadastro sincronizado nacional e participação de MPEs em compras públicas governamentais.

A parte principal dos debates, na Câmara, ocorreu na tramitação na Comissão Especial, tendo como interlocutores, de um lado, os representantes do Sebrae, da Frente Empresarial e da Frente Parlamentar e, de outro, os representantes da Receita Federal e do Confaz. Em depoimento ao Sebrae (Sebrae, 2007: 54), Hauly afirmou que foram realizadas mais de 40 reuniões apenas com a Receita Federal. As questões envolviam o valor da renúncia fiscal provocada com o Simples Nacional - que, para seus defensores, seria rapidamente compensada pela formalização de novos negócios - e o receio de alguns estados (principalmente os menores) e municípios de perderem receita com este novo regime. $\mathrm{O}$ argumento, ao qual seus partidários recorreram mais uma vez, foi que a perda seria momentânea e apenas para a Receita Federal.

No Senado, o projeto da Lei Geral foi encaminhado para a Comissão de Assuntos Econômicos, cujo relator era o senador Luiz Otávio e foi aprovado com 55 votos a favor e nenhum voto contra, mas com a inclusão de 34 emendas, sendo 14 de mérito e 20 de redação. A casa alterou a entrada em vigor do Simples Nacional, que passou de $1^{\circ}$ de janeiro para $1^{\circ}$ de julho do ano seguinte. Segundo a Receita Federal e o Confaz, (Folha de São Paulo, 2006a) não haveria tempo de implementar o Simples Nacional, que exigia um sistema informatizado para calcular a distribuição dos recursos para Estados e municípios, e cuja responsabilidade ficaria com a Receita Federal. Para a União e os governos estaduais e municipais, o adiamento em seis meses da entrada em vigor do Simples Nacional era benéfico, uma vez que minimizaria as perdas de arrecadação, sobretudo pelo fato de que seus orçamentos não previam tal renúncia.

A matéria retornou então à Câmara onde se deu a votação definitiva, em 22 de novembro, com 323 votos a favor, nenhum contra e quatro abstenções.

Uma das maiores preocupações da Receita Federal durante as negociações da Lei Geral foi evitar que a 
inclusão de profissionais liberais no Simples Nacional levasse assalariados a se tornarem pessoas jurídicas a fim de obter tributação menor (Folha de São Paulo, 2006b). A Receita também se preocupava com a renúncia tributária advinda deste regime:

\begin{abstract}
Ocorreram lances memoráveis no debate para provar aos técnicos da Receita que a renúncia fiscal prevista na lei seria rapidamente compensada pela formalização de novos negócios, bem como para persuadir os secretários da Fazenda estaduais e municipais de que haveria perdas momentâneas apenas para a Receita Federal, sem afetar os demais entes federados (Sebrae, 2007: 17).
\end{abstract}

Diferente do Simples Federal que foi instituído a partir de uma medida provisória, o Simples Nacional resultou de uma lei complementar, que, pelo quórum exigido para aprovação, demandou esforço maior de negociação. Após a aprovação, o passo seguinte era cuidar da sua implementação.

Silas Santiago, Secretário Executivo do CGSN, publicou um livro contando os embates inicias na implementação do Simples Nacional (Santiago, 2011). Segundo ele, o primeiro embate foi a data de abertura para entrada de empresas no Simples Nacional. Estados e municípios queriam que a opção estivesse disponível apenas em janeiro de cada ano, o que modificaria a previsão de vigência do sistema de julho de 2007 para janeiro de 2008. Para eles, só poderiam entrar em julho de 2007 as empresas que já faziam parte do Simples Federal. Na reunião posterior, em 30 de maio de 2007, foi aprovada, através da Resolução ${ }^{\circ} 4$ do CGSN, a permissão de opção pelo sistema em julho de 2007 (Santiago, 2011; Sebrae, 2011).

Santiago (2011) chama atenção para a sistemática de cálculo, pagamento e distribuição de recursos do Simples Nacional como única no Brasil. Ele afirma que

[...] não havia paralelo desse modelo no sistema de arrecadação federal, e isso com certeza influenciou positivamente a RFB na busca de melhores soluções para sua arrecadação [...] (Santiago, 2011: 18).

Decidiu-se, de comum acordo, pela criação de um novo documento de arrecadação que seria o Documento de Arrecadação do Simples Nacional (DAS). A parte complicada foi a formulação do modelo de arrecadação e distribuição dos recursos, uma vez que Estados e municípios não aceitavam a proposta da União de que se utilizasse, inicialmente, o modelo que já operava com a Secretaria do Tesouro Nacional (STN) repassando os valores para os demais entes federados (Santiago, 2011; Sebrae, 2011).
Estados e municípios defendiam um modelo no qual o valor fosse distribuído pelo próprio banco arrecadador, diretamente e sem intermediação (Santiago, 2011: 19). Sobre a negociação entre os entes federados, Santiago revela:

É preciso salientar que Estados e Municípios
nutriam grande desconfiança com relação à
Receita Federal do Brasil, e esse sentimento durou
um tempo que parecia nunca terminar. Houve
muitos e desagradáveis conflitos, principalmente
no primeiro ano. Eles imaginavam que a RFB
iria dominar as ações e as decisões do Simples
Nacional, e teriam necessariamente de mostrar
força, principalmente no início do processo.
Por pelo menos duas vezes fomos acusados de
má-fé por representante dos entes federativos, e
tivemos de bater com veemência. Mas sabíamos
que palavras não provariam nada, e precisaríamos
demonstrar, com ações, que merecíamos confiança
(Santiago, 2011: 18-19).

Foram realizadas reuniões com participação do Serpro, Servio Federal de Processamento de Dados, do Grupo Técnico de Arrecadação, da Coordenação-geral de Arrecadação da RFB e também, inicialmente, com a Febraban, Federação Brasileira de Bancos, e reuniões em separado com Banco do Brasil e Caixa Econômica Federal. O comitê decidiu-se pelo Banco do Brasil como centralizador das operações. De acordo com o modelo construído os bancos repassariam os recursos financeiros ao Banco do Brasil, que receberia do SERPRO os dados com informações sobre valores e credores (União, Estados e municípios), e distribuiria os recursos de cada parte, dois dias após o pagamento no caixa.

A integração entre as administrações tributárias dos diferentes entes federados brasileiros enfrentou os seguintes desafios, elencados por Santiago (2011): os de natureza "jurídico-constitucionais; (os) relativos à autonomia dos entes federados subnacionais; (os) relativos à capilaridade ou à abrangência territorial e geográfica da integração; (e os) relativos à segurança e à acessibilidade" (Santiago, 2011: 25).

A resposta para os desafios jurídico-constitucionais da integração das administrações tributárias dos entes federados foi a modificação da Constituição por meio da Emenda Constitucional n ${ }^{\circ} 42 / 2003$, e que resultou na Lei Geral da MPE instituindo o Simples Nacional e determinando o compartilhamento de cadastro, de arrecadação, de cobrança e de fiscalização.

$\mathrm{O}$ segundo desafio relativo à autonomia dos entes federados foi superado, segundo Santiago (2011), com um conjunto de medidas. A primeira é a gestão compartilhada, exercida através do CGSN, que como vimos, é um órgão colegiado, com poderes de 
regulação, e composto por representante da União, Estados e municípios.

As deliberações [do CGSN] são tomadas por quorum privilegiado, fazendo com que se busque o consenso para chegar a qualquer decisão. Com isso, os entes federados subnacionais têm poder efetivo sobre os assuntos relativos ao regime, não se subordinando de nenhuma forma aos interesses exclusivos do governo central (Santiago, 2011: 26).

A autonomia legislativa dos entes federados é assegurada na medida em que cada um deles pode legislar sobre as alíquotas dos impostos como ICMS e ISS, respeitando, no entanto, os percentuais destas alíquotas definidas na Lei Geral. É possível que Estados e municípios concedam benefícios maiores do que o estipulado na lei, conferindo uma autonomia, que embora não seja plena, possibilita que os entes administrem esses impostos dentro dos limites estabelecidos.

Os diferentes entes federados possuem autonomia operacional, atuando efetivamente, sobre decisões relativas à execução do Simples Nacional, como, por exemplo, a fiscalização das obrigações tributárias das empresas. Ressalta-se, porém que os Estados e municípios não podem decidir não participar do Simples Nacional.

A forma encontrada pelo legislador para diminuir o impacto do Simples Nacional nos entes da federação, principalmente em estados menores, foi a definição de sublimites regionais de acordo com a participação dos Estados no PIB, conforme visto anteriormente, subscrevendo o postulado de Arretche (2007) que estes têm autonomia política, mas não autonomia sobre as políticas. Tratava-se de uma nova política nacional que se instalava em um Estado federado com profundas desigualdades que, dessa maneira, foram equalizadas. Outras políticas nacionais, especialmente na área de educação, saúde e assistência social têm outras maneiras de compensar as desigualdades entre Estados e municípios em geral, baseadas em múltiplos critérios.

Oliveira (2007), por exemplo, estuda os Consórcios Intermunicipais de Saúde como mecanismo para superação de problemas do federalismo brasileiro, tais como a desigualdade municipal e a cooperação. Ao examinar o processo de descentralização das políticas de saúde nos municípios, a autora o divide em duas fases: descentralização autonomista (que vai de 1990 a 1998) e a descentralização dirigida (após 1998), mais centralizada, concluindo que ambas não foram capazes diminuir as desigualdades inter e intra-regionais.
Para resolver os desafios relativos à capilaridade e abrangência geográfica foi utilizada uma plataforma tecnológica única e acessível a todos os entes federados pela internet. Os aplicativos utilizados pelos entes federados estão disponíveis no Portal do Simples Nacional, com seções de acesso exclusivo das administrações tributárias para execução de procedimentos de operação do regime (Santiago, 2011: 27).

Por fim, para garantir a segurança e acessibilidade o CGSN determinou que o acesso, por todos os entes, aos aplicativos fosse realizado por meio de certificação digital, além de criar controles de acesso, com definição de classes de usuários e perfis de acesso. As permissões para o acesso são descentralizadas, sendo os Estados, os municípios e o Distrito Federal os responsáveis por determinar individualmente os usuários em cada aplicativo (Santiago, 2011: 28).

Em agosto de 2007, os primeiros valores arrecadados com o Simples Nacional foram distribuídos à União, Estados e municípios. No entanto, assim que o sistema foi implantado ocorreram discussões e queixas relativas ao aumento da carga tributária para as empresas prestadoras de serviços, enquadradas no anexo IV e V, outros apontaram a complexidade das regras e deficiência no atendimento dos órgãos públicos para solucionar pendências. Os regimes e benefícios de ICMS e ISS que existiam nos Estados e municípios foram revogados com a Lei Geral e resultaram, em alguns casos, em aumento da carga tributária, já que em determinados Estados e municípios havia isenção destes impostos. Os entes subnacionais deveriam aprovar uma legislação fazendo ajustes para manter ou melhorar os benefícios concedidos anteriormente.

Abreu (2008), em seu estudo sobre federalismo fiscal, citou as críticas de Carlos Dias, Diretor da Federação das Indústrias do Estado do Rio Grande do Sul (FIERGS) sobre o Simples Nacional, que identificou um aumento da carga tributária em muitas empresas que faziam parte do novo regime no Rio Grande do Sul, alem de criticar

[...] as inúmeras alterações do Comitê Gestor, na normatização tributária, torna[ndo] o sistema inseguro para os negócios, pois tudo pode mudar de uma hora a outra [...] (Abreu, 2008: 123).

Como vimos, mudanças na legislação tem procurado melhorar o ambiente geral, embora não tenha sido uma tarefa simples.

De acordo com o Sebrae (2011), que realiza o acompanhamento da implementação da Lei Geral, um regime especial de tributação mais benéfico foi implementado nos Estados do Amazonas, Distrito 
Federal, Maranhão, Sergipe, Paraíba, Rio de Janeiro, Paraná e Rio Grande do Sul.

Um desafio presente ao Simples Nacional são os Estados que exigem, indiscriminadamente, a substituição ou antecipação tributária do ICMS, causando dificuldades para a pequena empresa (SEBRAE, 2011). Segundo Nogueira (2009), o Sebrae buscou acabar com o ICMS antecipado e conseguiu que as regras fossem aperfeiçoadas e bem definidas, mas a cobrança permanece como decisão dos estados.

Em depoimento ao Sebrae (Sebrae, 2011: 70), André Spínola, gerente-adjunto de políticas públicas do Sebrae, relata distorções em alguns estados, abusando da substituição tributária e da cobrança do ICMS nas fronteiras. Outro ponto é que, apesar da revogação dos regimes que eram praticados nos estados antes da Lei Geral, é previsto a manutenção ou melhoria desses benefícios alterando a forma de cobrança. No entanto, alguns estados resistiram a manter os mesmo incentivos concedidos anteriormente, acabando com isenção que concediam do ICMS e provocando aumento da carga tributária. Segundo Spínola, Sergipe, Paraná e Rio de Janeiro fizeram ajustes necessários, melhorando inclusive os benefícios. Bahia e Amazonas são apontados como casos de regulamentação parcial. Também informa que, em relação ao ICMS, nenhum estado brasileiro teve recuo na arrecadação tributária após a vigência do novo regime (Sebrae, 2011: 70). Entretanto, a análise aqui apresentada não incluiu a discussão dos trabalhos que tratam dos resultados iniciais do Simples Nacional, mas não há dúvida acerca de seu apelo. Em 2008, haviam 2.917.926 empresas inscritas no Simples Nacional, no ano seguinte o número de inscritos foi de 3.386.255 e, até maio de 2012, existiam 6.394.206 empresas no Simples Nacional.

Dessa forma, podemos dizer que a adesão tem tido grande aceitação, ainda assim, uma avaliação mais completa depende da relação de sua eficácia com a geração de empregos, formalização e criação de novas empresas. A sistematização dos resultados alcançados com o Simples Federal de 1996 a 2007 e o desempenho do Simples Nacional contribuirão para uma análise dos caminhos e escolhas que tem sido feitos na implementação deste novo regime, o que escapa aos objetivos deste trabalho.

Mais do que isso, não é demais concluir esta parte com a questão dos custos difusos de uma política como esta, que opera por meio de renúncia fiscal. Neste, como em outros casos, tais custos difusos são difíceis de serem medidos e, no caso das MPEs, a contrapartida à renúncia seria o aumento da formalização destas empresas, o que impacta a arrecadação da previdência social.
No Brasil, em um estudo como consultora de orçamento e fiscalização financeira da Câmara dos Deputados, Pureza (2007) mostra que as MPEs (através do Simples Federal) são as maiores beneficiárias de políticas de renúncia fiscal, vindo, em segundo lugar, as entidades sem fins lucrativos e, em terceiro, as empresas industriais localizadas na Zona Franca de Manaus. Juntas, elas respondiam por 53\% do total da renúncia de receita tributária prevista para 2007 na esfera federal, estimada em R \$ 64,9 bilhões.

Em estudo mais recente sobre incentivos fiscais destinados ao desenvolvimento econômico e regional do Brasil, promovido pela consultoria da Câmara dos Deputados, Maciel (2010) apresentou dados sobre o Simples Nacional, que incluíam as modificações sofridas com a legislação posterior (Lei Complementar $\left.n^{\circ} 128 / 2008\right)$. Como indicamos anteriormente, essa lei ampliou o alcance do Simples Nacional, ao abranger, por exemplo, novos segmentos econômicos e criar o Microempreendedor Individual. Segundo o autor, o Simples Nacional representava a maior renúncia tributária da União, sendo que o volume previsto para 2009 era da ordem de $\mathrm{R} \$ 25,7$ bilhões de um total de $\mathrm{R} \$ 102$ bilhões. A região Sudeste seria responsável por $57 \%$ desta renúncia, seguida da região Sul com $23 \%$, do Nordeste (11\%), do Centro-Oeste $(6 \%)$ e, por último, da região Norte com $3 \%$.

O tema da renúncia tributária também foi pesquisado por Mancuso, Iglecias e Castro (2006) que analisaram a concessão de benefícios tributários a setores empresariais no período 1988-2005. A hipótese dos autores é que os benefícios tributários concedidos pela União aos empresários industriais se caracterizam por constituírem um conjunto de decisões ad hoc, com forte pressão política dos interessados. A tese apresentada não se atém ao tratamento tributário oferecido às MPEs - que não trata apenas de renúncia fiscal, mas também de processos de simplificação desta tributação -, mas envolve também outros campos de atuação.

No entanto, o trabalho de Mancuso, Iglecias e Castro (2006) apresenta um aspecto importante deste tipo de política, que está presente também no caso das MPEs, e que se refere à ausência de indicadores de eficiência, eficácia e transparência na concessão de benefícios tributários no Brasil. Em estudo posterior sobre o tema, Mancuso, Gonçalves e Mecarini (2010) mostraram que, no Brasil, a concessão de benefícios tributários ao empresariado é frequente, o montante da renúncia é elevado, além de apresentar riscos de rent seeking e baixa transparência no processo política de concessão, o que relativiza as possíveis virtudes do Simples Nacional, pelo menos até que essas perguntas possam ser respondidas. 


\section{Considerações Finais}

O Simples Nacional começou a ser formulado em 2003 em função das discussões sobre a reforma tributária e foi implementado, efetivamente, em 2007, porém com alterações e ajustes subsequentes. A participação do Legislativo e Executivo dos diversos entes federados na formulação e implementação nesta política pública são a fonte de seu caráter federativo, pois uma das características da distribuição intergovernamental da autoridade tributária e fiscal é a autonomia dos governos para legislar sobre seus próprios tributos, conforme foi determinado pela Constituição de 1988 (Arretche, 2005: 77).

Com o Simples Nacional ocorreu uma integração da administração tributária desses entes de uma forma inexistente até então, a despeito de um processo que enfrentou resistências e desconfianças em relação à preservação da autonomia de cada participante. Conforme apontou Nassif (2003), o Simples Nacional pode ser visto como um teste para as discussões sobre a viabilidade do Imposto Agregado e como um exercício de coordenação, cobrança, arrecadação e fiscalização conjunta. Superar a desconfiança vigente é um passo importante nas discussões posteriores sobre a reforma tributária e sobre o modelo atual.

No caso em pauta, foi decisivo o papel do Comitê Gestor neste processo, que mesmo com uma representação maior da União, oferece espaço e voz para representantes dos entes federados. Também foram organismos de apoio importantes, embora não discutidos neste paper, o Fórum Permanente da Micro e Pequena Empresa, que abriga dezenas de entidades e é coordenado pelo Ministério de Desenvolvimento, Indústria e Comércio Exterior, e a Frente Parlamentar de Apoio à Micro e Pequena Empresa, integrado por vários deputados e senadores.

Mas não apenas isto, pois os intrumentos técnicoadministrativos criados foram igualmente relevantes na equalização dos custos e benefícios dos estados e municípios, ou seja, contribuíram para superar os impasses políticos decorrentes das grandes diferenças entre as unidades subnacionais.

Em relação à administração tributária, o Simples Nacional (e mesmo o Federal) representa uma redução de custos de fiscalização, diminuição de documentos de arrecadação e diminuição da sonegação. De forma geral, trata-se de uma iniciativa inovadora, que avançou na definição de uma política tributária que conjuga autonomia e coordenação, reforçando as possibilidades de concretização de políticas públicas através desses dois elementos, junto ao controle interno, aspectos que foram ressaltados por Abrucio e Franzene (s. d.).

Esta análise contribuiu para os estudos de políticas públicas ao examinar o Simples Nacional, que é uma política ambiciosa para o segmento das
MPEs, reforçando as formulações já feitas a essa área temática, pois o estudo corrobora o diagnóstico de Arretche (2007) que mostra que, no nosso federalismo, há uma distinção entre autonomia política e autonomia sobre políticas, esta monopolizada pela União nas políticas públicas descentralizadas. Frente aos Estados, municípios e Distrito Federal, a Federação assegura para cada ente, poder político, administrativo, tributário, orçamentário e fiscal, mas pode manter um controle das políticas executadas pelos poderes subnacionais ao definir regras para a execução desse poder.

Assim se configurou o Simples Nacional, pois apesar de requerer um modelo de gestão compartilhada com a participação dos entes federados de diferentes níveis na administração do sistema, deveria seguir alguns preceitos definidos na Lei Geral das MPEs, como a exigência de todos fazerem parte do Simples Nacional, o respeito aos limites mínimos das faixas de enquadramento das MPEs a partir da participação do Estado no PIB, assim como, as alíquotas mínimas estipuladas nas tabelas de tributação. Além disso, a presença majoritária da União na composição do CGSN (quatro membros representando a União, dois os Estados e dois os municípios), e a grande disparidade regional do país, fortalece o papel do governo federal na gestão do Simples Nacional.

Não surpreende que a primeira tentativa de inclusão de Estados e municípios no Simples Federal, através da possibilidade de convênios destes com a União, não foi concretizada e, no caso do Simples Nacional, foi possibilitada com a aprovação da EC n ${ }^{\circ} 42 / 2003$, que previa a criação de um regime único de arrecadação dos tributos da União, Estados, Distrito Federal e Municípios. A partir desta emenda, iniciaram-se os esforços de formulação da lei complementar, enfrentando um complexo processo de negociações políticas, e da constituição de um sistema de informações que permitisse a manutenção da autonomia dos governos territoriais (Guimarães, 2011).

\section{Referências}

Abreu, Jorge Ritter de. 2008. Federalismo Fiscal e Coordenação: Análise da Política Tributária no Arranjo Federativo Brasileiro. Dissertação (Mestrado), Pontifícia Universidade Católica do Rio Grande do Sul.

Abrucio, Fernando Luiz e Franzese, Cibele (s.d.). Federalismo e Políticas Públicas: o impacto das relações intergovernamentais no Brasil. Disponível em: <http://www.defesasocial.rn.gov.br/ contentproducao/aplicacao/searh_escola/arquivos/ pdf/paper-federalismo-fernando-abrucio.pdf $>$. Acesso em: 11 abr. 2012. 
Arretche, Marta. 2004. Federalismo e Políticas Sociais no Brasil: Problemas de Coordenação e Autonomia. São Paulo em Perspectiva, 18(2): 17-26.

Arretche, Marta. 2005. Quem Taxa e Quem Gasta: A Barganha Federativa na Federação Brasileira. Revista de Sociologia e Política, 24: 69-85.

Arretche, Marta. 2007. Federalismo, políticas e instituições: o Brasil em perspectiva comparada. In E. Diniz (org.), Globalização, Estado $e$ Desenvolvimento - Dilemas do Brasil no Novo Milênio. Rio de Janeiro: Editora da Fundação Getúlio Vargas, p. 263-300.

Brasil. Ministério da Fazenda. 2003a. Proposta de Emenda Constitucional n ${ }^{\circ} 41$, de 30 de abril de 2003. Altera o Sistema Tributário Nacional e dá outras providências. Diário Oficial da República Federativa do Brasil, Brasília, DF, abr.

Brasil. Ministério da Fazenda. 2003b. Emenda Constitucional $n^{\circ} 42$, de 19 de dezembro de 2003. Altera o Sistema Tributário Nacional e dá outras providências. Diário Oficial da República Federativa do Brasil, Brasília, DF, 31 dez.

Brasil. Câmara dos Deputados. 2004a. Projeto de Lei Complementar $\mathrm{n}^{\circ} 123$. Regulamenta o parágrafo único do art. 146 e o inciso IX do art. 170 da Constituição Federal e dá outras providências. Diário Oficial da República Federativa do Brasil, Brasília, DF, jan.

Brasil. Câmara dos Deputados. 2004b. Projeto de Lei Complementar $\mathrm{n}^{\circ} 125$. Regulamenta o parágrafo único do art. 146 e o inciso IX do art. 170 da Constituição Federal e dá outras providências. Diário Oficial da República Federativa do Brasil, Brasília, DF, ago.

Brasil. Ministério da Fazenda. 2006. Lei Complementar $\mathrm{n}^{\circ} 123$, de 14 de dezembro de 2006. Institui o Estatuto Nacional da Microempresa e da Empresa de Pequeno Porte; altera dispositivos das Leis nos 8.212 e 8.213, ambas de 24 de julho de 1991, da Consolidação das Leis do Trabalho - CLT, aprovada pelo Decreto-Lei no 5.452 , de 1 o de maio de 1943 , da Lei no 10.189 , de 14 de fevereiro de 2001, da Lei Complementar no 63, de 11 de janeiro de 1990; e revoga as Leis nos 9.317, de 5 de dezembro de 1996, e 9.841, de 5 de outubro de 1999. Diário Oficial da República Federativa do Brasil, Brasília, DF, 15 dez.

Brasil. Ministério da Fazenda. 2007. Decreto n ${ }^{\circ}$ 6.038, de 7 de fevereiro de 2007. Institui o Comitê Gestor de Tributação das Microempresas e Empresas de Pequeno Porte, e dá outras providências. Diário Oficial da República Federativa do Brasil, Brasília, DF, 08 fev.

Brasil. Ministério da Fazenda. 2008. Lei Complementar $\mathrm{n}^{\circ} 128$, de 19 de dezembro de 2008. Altera a Lei Complementar $\mathrm{n}^{\circ} 123$, de 14 de dezembro de 2006, altera as Leis $n^{\circ} 8.212$, de 24 de julho de 1991, 8.213, de 24 de julho de 1991, 10.406, de 10 de janeiro de 2002 - Código Civil, 8.029, de 12 de abril de 1990, e dá outras providências. Diário Oficial da República Federativa do Brasil, Brasília, DF, 22 dez.
Brasil. Ministério da Fazenda. 2009. Lei Complementar $\mathrm{n}^{\circ} 133$, de 28 de dezembro de 2009. Altera a Lei Complementar no 123, de 14 de dezembro de 2006, para modificar o enquadramento das atividades de produções cinematográficas, audiovisuais, artísticas e culturais no Regime Especial Unificado de Arrecadação de Tributos e Contribuições devidos pelas Microempresas e Empresas de Pequeno Porte. Diário Oficial da República Federativa do Brasil, Brasília, DF, 29 dez.

Brasil. Ministério da Fazenda. 2011. Lei Complementar $\mathrm{n}^{\circ} 139$, de 10 de novembro de 2011. Altera dispositivos da Lei Complementar $n^{\circ} 123$, de 14 de dezembro de 2006, e dá outras providências. Diário Oficial da República Federativa do Brasil, Brasília, DF, 11 nov.

Faria, Carlos Aurélio Pimenta. 2003. Idéias, conhecimento e políticas públicas: um inventário sucinto das principais vertentes analíticas recentes. Revista Brasileira de Ciências Sociais, 18(51): 21-29.

Folha de São Paulo. 2006a. Sob pressão, governo adia o Supersimples. Folha de São Paulo, São Paulo, 8 nov. Disponível em: <http://www1.folha.uol.com. br/fsp/dinheiro/fi0811200609.htm>. Acesso em: 30 mar. 2009.

Folha de São Paulo. 2006b. Vetos tiram corretores, decoradores, vendedores e fogos do Supersimples. Folha de São Paulo, São Paulo, 16 dez. Disponível em: <http://www1.folha.uol.com.br/fsp/dinheiro/ fi1612200608.htm>. Acesso em: 30 mar. 2009

Guimarães, Fabrícia. 2011. As Políticas de Apoio às Micro e Pequenas Empresas no Brasil: O Caso da Lei Geral de 2006. Tese (Doutorado), Universidade Federal Fluminense.

Maciel, Marcelo Sobreiro. 2010. Política de Incentivos Fiscais: quem recebe isenção por setores e regiões do país. Brasília: Consultoria Legislativa da Câmara dos Deputados.

Mancuso, Wagner; Iglecias, Wagner e Castro, Simone. 2006. Lobby e renúncia tributária da União: contribuições para uma análise da política de concessão de benefícios tributários ao empresariado industrial no Brasil (1988-2005). Caxambu, Encontro Anual da Associação Nacional de Pós-Graduação e Pesquisa em Ciências Sociais.

Mancuso, Wagner; Gonçalves, Maetê e Mecarini, Fabrizio. 2010. Colcha de retalhos: a política de concessão de benefícios tributários ao empresariado no Brasil (1988-2006). In W. Mancuso, M. A. Leopoldi e W. Iglecias (orgs.), Estado, empresariado e desenvolvimento no Brasil: novas teorias, novas trajetórias. São Paulo: Editora de Cultura, p. 213-237.

Menicucci, Telma. 2007. A Implementação da Reforma Sanitária: a formação de uma política. In G. Hochman, M. Arretche e E. Marques (orgs.), Políticas Públicas no Brasil. Rio de Janeiro: Editora Fiocruz, p. 303-325.

Nassif, Luis. 2003. Laboratório para o futuro. Folha de S. Paulo, 03 out. Disponível em: <http://www1.folha. uol.com.br/fsp/dinheiro/fi0310200308.htm>. Acesso em: 11 jul. 2009. 
Nogueira, Walcir Marçal. 2009. ICMS, substituição tributária e competição entre Estados. Última Instância. Disponível em http://ultimainstancia.uol.com.br/ conteudo/artigos/4500/artigos+ultimainstancia. shtml>. Acesso em: 8 abr. 2012.

Oliveira, Vanessa Elias. 2007. O Municipalismo Brasileiro e a Provisão Local de Políticas Sociais. $O$ Caso dos Serviços de Saúde Pública nos Municípios Paulistas. Tese (Doutorado), Universidade de São Paulo.

Pureza, Maria Emilia Miranda. 2007. Disciplinamento das renúncias de receitas federais: inconsistências no controle dos gastos tributários. Estudo Técnico elaborado por consultor orçamentário. Brasília: Câmara dos Deputados.

Sarak, Denis. 2010. Federalismo Fiscal e Políticas de Cooperação Intergovernamental Fiscal. Revista de Estudos Jurídicos UNESP, 14(20): 171-183.

Santiago, Silas. 2011. Simples Nacional: o exemplo de federalismo fiscal brasileiro. São Paulo: Saraiva.
Sebrae. 2004. Rumo à Lei Geral da Pequena Empresa. Brasília: Serviço Brasileiro de Apoio às Micro e Pequenas Empresas.

Sebrae. 2007. Lei Geral das Micro e Pequenas Empresas. A história de uma lei que veio fazer História. Brasília: Serviço Brasileiro de Apoio às Micro e Pequenas Empresas.

Sebrae. 2011. 3 Anos da Lei Geral da Micro e Pequena Empresa. Brasília: Serviço Brasileiro de Apoio às Micro e Pequenas Empresas.

Silva, Adriano da Nóbrega Silva. 2005. Supersimples - análise dos projetos sobre a nova tributação da microempresa e da empresa de pequeno porte. Consultoria legislativa, Câmara dos Deputados.

Viol, Andréa Lemgruber e Rodrigues, Jefferson José. 2000. Tratamento Tributário da Micro e Pequena Empresa no Brasil. Brasília: Ministério da Fazenda, Secretaria da Receita Federal, CoordenaçãoGeral de Estudos Econômico-Tributários. 